\title{
Digital motivations: from being entertained to be happy to learn Why do children and teenagers play videogames and can those motivations be canalized towards educational purposes?
}

\author{
Tamás Pólya \\ ${ }^{1}$ Eszterházy Károly College, Department of Communication and Media Studies, Hungary, 3300, Eger, \\ Eszterházy tér 1. \\ E-Mail:polya@ektf.hu \\ * Author to whom correspondence should be addressed; Tel.: +36-36-520-400; Fax: +36-36-520-400 \\ Accepted:
}

\section{Introduction}

Children and teenagers today use digital gadgets and platforms on an everyday basis and they appear to be vigorously motivated to do so. Videogames are one of the most popular types of digital media enjoyed by young people. Most of them seem to choose videogames primarily for being entertained but a growing number of applications (serious and educational games) are geared towards serving educational purposes both inside and outside the school environment.

My proposed talk focuses on the issue of psychological motivations of play. What are the driving forces behind young people's use of videogames in general and whether, specifically, can those motivations be canalized towards the use of serious or educational games? To put it in other words, is there a chance that good game design will bring videogame players to use educational software and digital learning tools with as much enthusiasm as they immerse themselves in game worlds created for entertainment purposes?

I shall examine this problem by looking at the results of two different studies we made in Hungary, in 2013 and 2014, respectively. One study concerned, among others things, the long-term and shortterm motivations of elementary school children playing motion controlled videogames on a voluntary basis. The other was a general and representative survey of videogame playing habits and attitudes 
among Hungarian youth aged 8-18, taken in 2014. In both cases, uncovering the motivations for play was an important goal of the study.

Obviously, there is a large research tradition aimed at identifying the motivations to play in the case of videogames. One strand of valuable research seems to be more theoretical and intuitive in nature, and has the potential use of games for educational purposes more clearly in sight (e.g. Malone 1980, Prensky 2001, Gee 2003). Another strand is of a more descriptive and empirical kind and typically focuses on exploring the motivations of fans of specific videogame genres such as MMORPGs by using surveys (e.g. Yee 2006, and Olson 2010 for a review). In designing the studies described here we followed the second strand of research and tried to gauge players' motivations without using predefined categories in the survey questions and thus letting them express their motivations in their own words. But after having interpreted the answers one can see motivating elements emerge that square also with what the first tradition of research proposes as chief motivating factors (e.g. fun and enjoyment, Prensky 2001; fantasy, Malone 1980).

\section{Methods}

Please see in next section under (Study 1.) and (Study 2.)

\section{Results and Discussion}

(Study 1.) In the framework of a longitudinal study we offered the opportunity for elementary school students in Eger, Hungary (second/third and fifth/sixth graders, age groups 8-9 and 11-12; $N=$ 59), to use motion controlled videogames on XBOX 360 game consoles equipped with a Kinect motion sensor. Starting in March 2013 and finishing in December 2013, students could play Kinect Sports and Kinect Adventures! during school weeks each afternoon but on a voluntary basis, under teacher supervision and filling out a brief survey ('game diary') each time they decided to come to play. Teachers were not allowed to play together with the children; they were only present to collect the game diaries and to make sure that gameplay proceeds without disputes. The study aimed at establishing (1) whether the children's motivation to play the motion controlled games remained constant in a relatively long period of time, i.e., one spanning two school terms; (2) what specific motivations did the children have when they came to play, and (3) whether playing motion controlled games on a regular basis would help children to maintain a healthy lifestyle.

As regards their motivations, we found that despite initial enthusiasm, about two thirds of the children dropped out of the study in the long run and that younger children ( $2^{\text {nd }}$ and $3^{\text {rd }}$ graders) enjoyed playing much more than did their older counterparts ( $5^{\text {th }}$ and $6^{\text {th }}$ graders). In all, we registered 754 occasions when younger students came to play and only 114 when members of the older age group choose to do so.

By looking at the data forthcoming from the game diaries we could also fathom some of the children's motivation for play. Interestingly, their motivations were not of a sporting or social nature: only on $6,3 \%$ of the occasions did the say they 'enjoyed doing some sport' and 'getting tired in a positive way', just as 'playing with friends' as a motivation featured very rarely $(2,9 \%)$ in the records. 
Rather, they mentioned on many occasions that they 'loved to play' $(30,1 \%)$ and 'playing was fun' or that it put them 'in a good mood' $(28,8 \%)$. Though it is not fully evident exactly what psychological motivations the children referred to when using phrases like these, it seems that on most occasions the participants in our study came to play motion controlled videogames primarily in order to be entertained and to have fun. Note though that this was a small sample and also that motion controlled sports games constitute a specific kind of videogames more on the arcade side, without a rich narrative and fantasy aspects typical of other popular genres such as MMORPGs and action-adventure games (cf. Malone 1980).

Examining the social dimension a bit further one finds that supervising teachers present at the gaming site described the children as helpful to each other on most of the occasions $(82,9 \%$ of the cases) and the kids themselves reported 'to have enjoyed playing with a gaming partner a lot' most of the time $(77,2 \%)$. In line with this, it was in less than $50 \%$ of the gaming occasions that children reported in the game diary that they 'wanted to win'. This difference might show that the children's motivation to be competitive was weaker than the intention of being a good sport, i.e. a cooperative playing partner.

(Study 2.) The other study I would like to bring to bear on the issue of gaming motivations was a general survey of videogame playing habits and attitudes among Hungarian youth aged 8-18. It was taken in 2014, between April and June, and was representative for gender, age, place of residence with a sample of over 690 subjects from various elementary and middle schools in Hungary. The participants filled out our online survey under teacher supervision as part of their class. Some questions of the survey concerned motivations for play. For example, participants were asked why they liked playing digital games (including mobile, PC and console games). Among the prominent answers, only one or two seems to be prima facie compatible with the kind of appeal educational games may typically offer. Thus, one of the motivating factors was 'the opportunity to practise English while playing' (63,9\%), another was 'to be able to play together with my friends and classmates' (55,6\%), both possibly offered by educational games. Apart from that, respondents stated that what they liked about playing videogames was: 'the atmospheric and enticing visual aspects of the games' (64,5\%); 'the pleasant immersion in the game world' (60,3\%); that they can 'forget about their problems while playing' (52,7\%); that they can 'let their anger out' $(48,2 \%)$; that games are 'an ideal topic of conversation with friends' $(46,8 \%)$; and that in the game they 'can be someone they cannot be in reality’ (44\%).

Similarly, when asked about what features or traits of their favourite avatar and/or favourite game character do they find most attractive, they replied that: they can be 'stronger or faster than in reality' (58,7\%); can do or accomplish 'things that are more spectacular than the ones in reality' $(53,4 \%)$; that they can be 'smarter than in reality' (40\%); or even that they can 'be naughty or behave badly towards others' $(35,4 \%)$. On the more positive side, many respondents mentioned that they appreciated their favourite avatar's or character's 'ability to help out others' $(44,7 \%)$ as well.

Also, when asked about 'why is it a good thing to play videogames', the majority of answers pointed towards amusement and entertainment-seeking rather than learning-related phenomena. For 
example, $45,3 \%$ of respondents mentioned immersion and exploration as the chief merit of games; that one can kill the time by playing them (20\%); that playing videogames relieves one's tension and frustration (18\%); and that gaming is a social form of entertainment (4,4\%). In all, 7,2\% of them said that gaming improves one's skills or can be used to learn something.

\section{Conclusions}

What seems to come forth from these studies is that many aspects of digital games that young people say they like are closely linked to, or even rooted in, the entertaining character of these games (e.g., offering an audio-visual spectacle, exceeding the bounds of reality, to offer the ability to wind down or behave in a naughty manner). And only some of the playing motivations reported or fathomed seem to square more readily with what a serious game or a digital learning tool is likely to offer (e.g. improvement of language skills; and possibly the social and fantasy aspects of play). Thus, getting the playing motivations of young people right and keep those motivations constantly high might prove to be a crucial and difficult task of educational digital games and game designers.

\section{Acknowledgments}

Both researches mentioned in this abstract were pursued within the framework of the TÁMOP4.2.2.C-11/1/KONV-2012-0008 (Social Renewal Operative Program) project titled The application of ICT in learning and knowledge acquisition: Research and Training Program Development in Human Performance Technology in Hungary, at Eszterházy Károly College, Eger. Said project was implemented by the support of the European Union and the co-financing of the European Social Fund. I also thank the anonymous reviewer of the abstract for his valuable comments and suggestions.

\section{References and Notes}

1. Malone, T. What makes things fun to learn? Heuristics for designing instructional computer games. In SIGSMALL '80 Proceedings of the 3rd ACM SIGSMALL symposium and the first SIGPC symposium on Small systems; ACM Press: New York, 1980; pp. 162-169.

2. Prensky, M. Digital Game-based Learning; McGraw-Hill: New York, 2001.

3. Gee, J. P. What Video Games Have to Teach Us About Learning and Literacy; Palgrave Macmillan: New York, 2003.

4. Yee, N. Motivations for Play in Online Games; CyberPsychology and Behavior 2006, 9, 772775.

5. Olson, C. K. Children's motivations for video game play in the context of normal development. Review of General Psychology 2010, 14 (2), 180-187.

(C) 2015 by the authors; licensee MDPI and ISIS. This abstract is distributed under the terms and conditions of the Creative Commons Attribution license. 